\title{
Research on Application of Risk Assessment Technology to 100,000-cubic-meter Crude Oil Storage Tanks
}

\author{
Fang Zhou ${ }^{a}$, Xing Shu ${ }^{b}$, Shen Gongtian ${ }^{c}$, Li Guanghai ${ }^{d}$, Yuan Yilin ${ }^{\mathrm{e}}$ \\ Hazardous Chemical Substance Equipment Division, China Special Equipment Inspection and \\ Research Institute, Beijing, P. R. China \\ ae-mail: fangzhou@csei.org.cn, be-mail: xingshu@csei.org.cn, 'e-mail: \\ shengongtian@csei.org.cn, de-mail: liguanghai@csei.org.cn, ee-mail: vilin1988@126.com
}

Keywords: Crude oil tanks, Risk assessment, Inspection strategy, 100,000 cubic meters

\begin{abstract}
Due to the large volume of storage tank at the national oil reserve base and its critical consequence of failure, its security issues are particularly prominent and are taken seriously by the government and the community. In this paper, the risk assessment technology is applied to 23 crude oil storage tanks whose nominal capacity are 100,000 cubic meters at a national oil reserve base. It is concluded that the wall plate and bottom plate of 23 storage tanks are expecting a certain period of risks at present and in the future. According to the acceptable level of risks of the reserve base and the damage mechanism and failure modes of different configuration items of storage tanks, the risk-based inspection strategy of 23 storage tanks is developed.
\end{abstract}

\section{Introduction}

In recent years, with the advances in the construction process of national strategic oil reserve bases in China, the safety of large atmospheric storage tank has become particularly important [1-3]. Due to its large volume and hazardous containing medium, the leakage will trigger major accidents such as fires and explosions, cause incalculable environmental damage and bring disastrous consequences [4-5]. Fig. 1 shows a photo of oil tank damage.

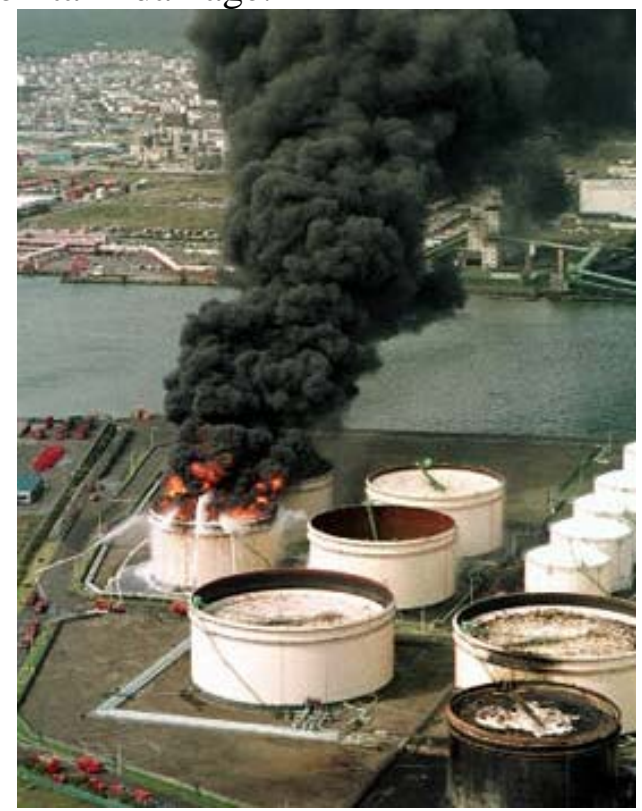

Fig 1 shows a photo of oil tank damage

At present, most of our inspection modes of storage tanks are still in the stage of periodic inspection, i.e., regularly test the dangerous chemical storage tanks according to periodic inspection plans. However, the periodic inspection has some drawbacks: on the one hand, the aging tanks which have greater risks cannot be tested in time, on the other hand, opening and inspection most of storage tanks with no serious defects will result in excess, which leads to unnecessary loss of production [6-7]. 
Therefore, the risk assessment of the storage tanks turns periodic inspection into risk-based inspection, which both ensures safe operation and has a great cost savings.

\section{Project Background}

23 storage tanks under the application of risk assessment are all aboveground atmospheric storage tanks. They are designed and constructed according to National Standards of P.R.C. for Design of Vertical Cylindrical Steel Welded Storage Tank SH 3046-92, National Standards of P.R.C. for Seismic Design of Steel Equipment in Petrochemical Industry SH 3048-99, National Standards of P.R.C. for Construction and Inspection for Vertical Cylindrical Steel Welded Storage Tank GBJ128-90, National Standards of P.R.C. for Construction and Inspection for Field Equipment and Industrial Pipeline Welding Engineering GB50236-98.

23 storage tanks are all floating-roof tanks, whose host materials include SPV490Q, 16MnR, Q235-B, and Q235-A; the containing medium for storage tank are crude oil, and time-to-use starts from August 2006 to April 2007. Basic information is shown in Table 1.

Table 1 Basic Information of Containing Medium (According to Tank No.)

\begin{tabular}{|c|c|c|c|c|c|c|}
\hline No. & Name & Origin & $\begin{array}{l}\text { Sulfur } \\
\text { content } \\
\mathrm{m} \% \\
\end{array}$ & $\begin{array}{c}\text { Acid } \\
\text { mgkoh/g }\end{array}$ & $\begin{array}{l}\text { Viscosity }(50 \\
\left.{ }^{\circ} \mathrm{C}\right) \mathrm{mm} 2 / \mathrm{s}\end{array}$ & $\begin{array}{l}\text { Storage tank number } \\
\text { with this medium }\end{array}$ \\
\hline 1 & $\begin{array}{l}\text { Iran light crude } \\
\text { oil }\end{array}$ & Iran & 1.50 & 0.12 & 6.10 & T-19, T-20 \\
\hline 2 & $\begin{array}{l}\text { Iran heavy crude } \\
\text { oil }\end{array}$ & Iran & 2.02 & 0.11 & 9.87 & T-25, T-26 \\
\hline 3 & Basra crude oil & Iraq & 2.92 & 0.14 & 10.63 & $\mathrm{~T}-36$ \\
\hline 4 & Ural crude oil & Russia & 1.4 & 0.06 & 6.76 & $\mathrm{~T}-41$ \\
\hline 5 & $\begin{array}{l}\text { Saudi light crude } \\
\text { oil }\end{array}$ & $\begin{array}{l}\text { Saudi } \\
\text { Arabia }\end{array}$ & 2.00 & 0.05 & 5.77 & $\begin{array}{l}\text { T-6, T-11, T-12, T-17, } \\
\text { T-18, T-23, T-24, T-29, } \\
\text { T-31, T-32, T-37, T-38, } \\
\text { T-43, T-44 }\end{array}$ \\
\hline 6 & Xirui crude oil & Iran & 1.90 & 0.07 & 6.35 & $\mathrm{~T}-30$ \\
\hline
\end{tabular}

The technical foundation of the risk assessment project in this paper includes: Safety Technical Regulation for Vertical Cylindrical Steel Welded Storage Tank AQ 3053-2015, Risk-Based Inspection and Evaluation for Atmospheric Storage Tank GB/T 30578-2014, Risk-Based Inspection API 580, Risk-Based Inspection Technology API 581, The Procedures for Operation, Maintenance and Repair of Vertical Cylindrical Steel Welded Tank SY/T5921-2011, and so on[8-10].

\section{Risk Calculation}

For risk calculation, DNV GL Onshore 5.3.2, a risk assessment software, is adopted to calculate the respective likelihood of failure and failure consequences of bottom plate and wall plate of tanks. According to the pattern of damage and failure mechanism, the injury parameter shall be determined in accordance with relevant regulations of API 581 and GB/t 30578 in order to calculate the likelihood of failure for each storage tank; in terms of the establishment of failure consequences, the main characteristics of medium and release rate, the environmental damage caused by the leakage of medium, groundwater pollution, losses of business interruption, personal injury and other factors should be taken into consideration; the levels of risk are determined on the grounds of the likelihood of failure and failure consequences. 
The risk matrix for the bottom plate and wall plate of 23 storage tanks at present (September 2016), in 5 years (September 2021) and in 10 years (September 2026) is shown in Fig. 1, Fig. 2 and Fig. 3.

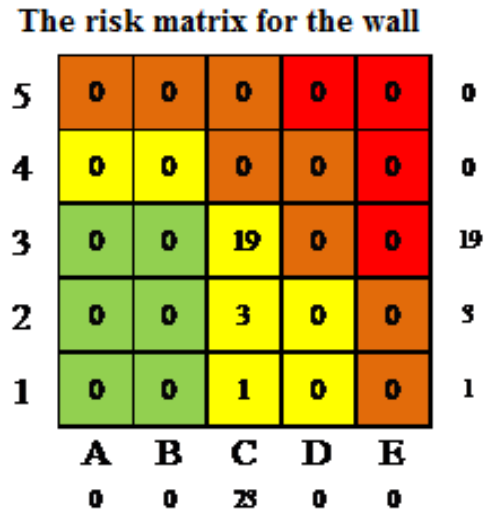

Failure consequence level

\begin{tabular}{|c|c|c|}
\hline Risk level & Total & Percent \\
\hline LLOW & 0 & $0 \%$ \\
\hline 2MIEDIIM & $\mathbf{3}$ & $100 \%$ \\
\hline 3MIEDIIM HIGH & 0 & $0 \%$ \\
\hline 4.HIGH & 0 & $0 \%$ \\
\hline Total & $\mathbf{2 3}$ & $\mathbf{1 0 0}$
\end{tabular}

The risk matrix for the bottom plate

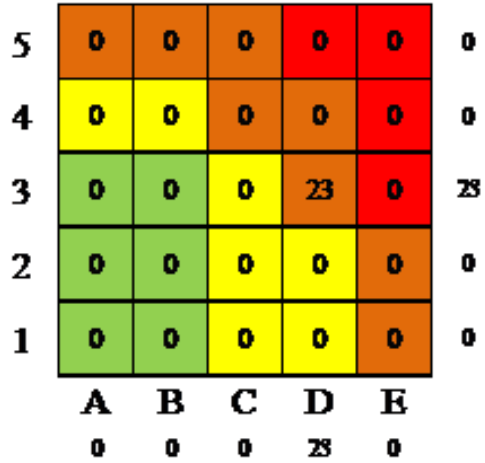

Failure consequence level

\begin{tabular}{|c|c|c|}
\hline Risk level & Total & Percent \\
\hline LLOW & 0 & $0 \%$ \\
\hline 2MIEDIUM & 0 & $0 \%$ \\
\hline BMIEDIUM HIGH & 23 & $100 \%$ \\
\hline 4.HIGH & 0 & $0 \%$ \\
\hline Total & $\mathbf{2 3}$ & $\mathbf{1 0 0}$
\end{tabular}

Fig. 1 The bottom plate and wall plate of storage tanks and risk maps in 2016

The risk matrix for the wall

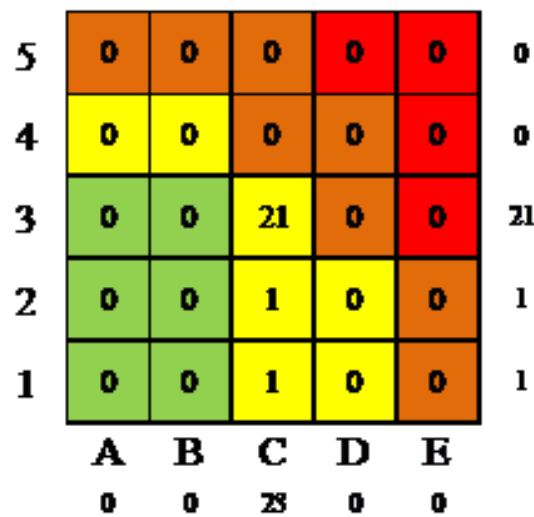

Failure consequence level

\begin{tabular}{|c|c|c|}
\hline Risk level & Total & Percent \\
\hline LLOW & $\mathbf{0}$ & $\mathbf{0 \%}$ \\
\hline 2MIEDIIM & $\mathbf{2 3}$ & $\mathbf{1 0 0 \%}$ \\
\hline BMIEDIIM HIGH & $\mathbf{0}$ & $\mathbf{0 \%}$ \\
\hline 4.HIGH & $\mathbf{0}$ & $\mathbf{0 \%}$ \\
\hline Total & $\mathbf{2 3}$ & $\mathbf{1 0 0 \%}$ \\
\hline
\end{tabular}

The risk matrix for the bottom plate

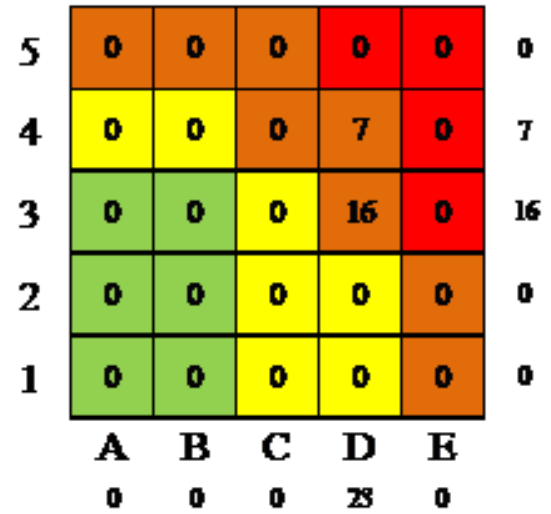

Failure consequence level

\begin{tabular}{|c|c|c|}
\hline Risk level & Total & Percent \\
\hline 1LOW & 0 & $0 \%$ \\
\hline 2MIEDIUM & 0 & $0 \%$ \\
\hline BMIEDIUM HIGH & 23 & $100 \%$ \\
\hline 4.HIGH & 0 & $0 \%$ \\
\hline Total & 23 & $100 \%$
\end{tabular}

Fig. 2 The bottom plate and wall plate of storage tanks and risk maps in 2021 


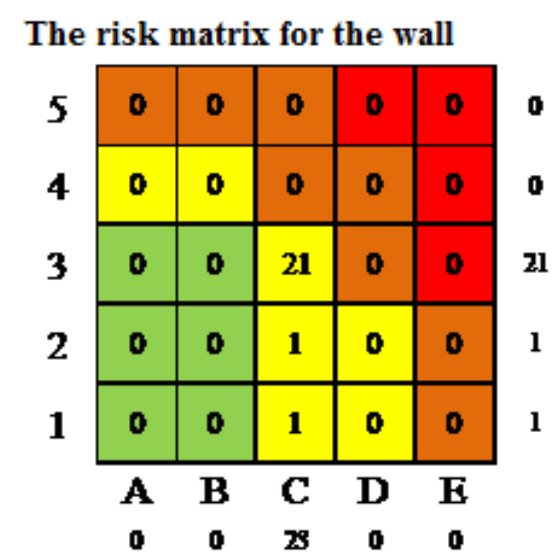

Failure consequence level

\begin{tabular}{|c|c|c|}
\hline Risk level & Total & Percent \\
\hline LLOW & 0 & $0 \%$ \\
\hline 2MIEDIM & 23 & $100 \%$ \\
\hline BMIEDIIM HIGH & 0 & $0 \%$ \\
\hline 4.HIGH & 0 & $0 \%$ \\
\hline Total & $\mathbf{2 3}$ & $\mathbf{1 0 0 \%}$
\end{tabular}

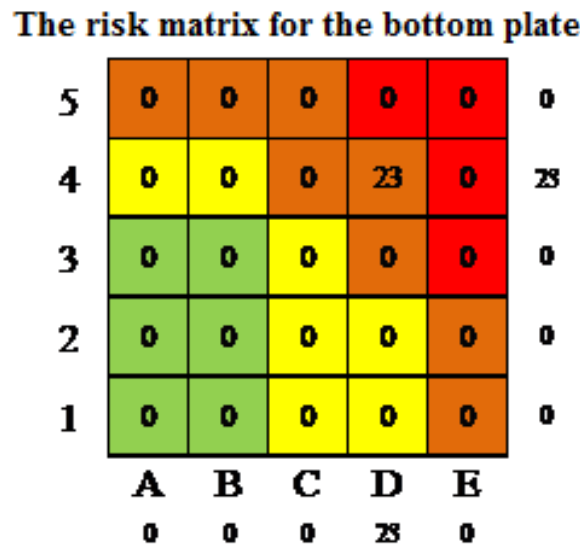

Failure consequence level

\begin{tabular}{|c|c|c|}
\hline Risk level & Total & Percent \\
\hline 1LOW & 0 & $0 \%$ \\
\hline 2MIEDIUM & 0 & $0 \%$ \\
\hline BMIEDIUM HIGH & 23 & $\mathbf{1 0 0 \%}$ \\
\hline 4.HIGH & 0 & $\mathbf{0 \%}$ \\
\hline Total & $\mathbf{2 3}$ & $\mathbf{1 0 0 \%}$
\end{tabular}

Fig. 3 The bottom plate and wall plate of storage tanks and risk maps in 2026

\section{Summary}

(1) The risk analysis involving a total of 23 units of atmospheric storage tanks, the current risk calculation results show that devices of the medium risk level are almost wall plate, and devices of the relatively high risks are mainly the bottom plates.

(2) According to the risk calculation results of the next 5 years and the next 10 years, devices of the medium risk level are almost wall plate, and devices of the relatively high risks are mainly the bottom plates

(3) After completing the assessment, online inspection can be done as planned according to the risk levels of storage tanks; and based on the online inspection results, the overall downtime inspection of storage tanks by opening the tanks can be properly arranged.

\section{Acknowledgment}

This work was supported in part by the financial from National key scientific instrument and equipment development project (Project No.2012YQ090175), the Science and technology projects of General administration of quality supervision, inspection and quarantine of P. R. China (AQSIQ), (Project No.2013QK018), (Project No.2014QK244), Quality inspection of public welfare scientific research Foundation of China (Project No.201310156), and PhDs Foundation (Project No.2016 nei21).

\section{References}

[1] Fang Z, Jia G D, Liu D Y. Study On Carburizing Inspection Of Cracking Furnace Tube Using Acoustic Emission Technique [C]. Proceedings of the ASME 2014 Pressure Vessels \& Piping Conference, 2014.

[2] Fang Z, Chen Z. P, Wang L. Study on high-temperature naphthenic acid corrosion of type 304 and type 316L stainless steel and their welded joints[C]. ASME Meeting. 5 (2009) 351-357. 
[3] Fang Z, Hu W.W, Liu D.Y. Study on Metallography Test of the Steel SPV490 for Atmospheric Storage Tank after Fire[C]. Proceedings of the ASME 2016 Pressure Vessels \& Piping Conference. 2016.

[4] Fang Z, Chen Z. P, Jia G D. Dynamic Experimental Investigation on the Self-Vibration Characteristics of Liquid Storage Tanks Under Seismic Excitations[C]. 2013 ASME Pressure Vessels and Piping Division Conference, July 14-18, Paris, France. ASME Pressure Vessels Piping, 2013.

[5] Fang Z, Chen Z P, Yan S J, et al. Ф $2800 \mathrm{~mm}$ nonmetal storage tank is a large earthquake simulation test of anchorage in Chinese. [J]. Pressure Vessels. 2012, 29(6):1-8.

[6] Fang Z, Chen Z. P. Effect of Weld on Axial Buckling of Cylindrical Shells. Advanced Materials Research, 2010, 223(4): 139-141, 171-175.

[7] Li G. H, Chen H.Y, Fang Z. Intgrity Management of Large Size Atmospheric Storage Tank. 2014 ASME Pressure Vessels and Piping Division Conference, July 20-24, 2014, Anaheim, California, USA. ASME Pressure Vessels Piping, 2014.

[8] American Petroleum Institute. API RP580 Risk based inspection[S]. 2009.

[9] American Petroleum Institute. API 581 Risk based inspection[S]. 2008.

[10]American Petroleum Institute. API 653 Tank Inspection, Rapir, Alteration, and Reconstruction [S] . 2009. 